\title{
A Fuzzy Rule-based Bargaining Model for Online Group Purchasing
}

\author{
Ping-Wen Chen ${ }^{1}$ Yung-Ming $\mathrm{Li}^{2}$ Ting-Kai Hwang ${ }^{3}$ \\ ${ }^{1}$ Department of Information Management, Southern Taiwan University of Technology \\ pwchen@mail.stut.edu.tw \\ ${ }^{2}$ Institute of Information Management, National Chiao Tung University \\ yml@mail.nctu.edu.tw \\ ${ }^{3}$ Department of Information Communication, Ming Chuan University \\ tkhwang@mcu.edu.tw
}

\begin{abstract}
Online group purchasing or collective purchasing is the activity in which people who desire to buy the same merchandises join together so that they can negotiate with sellers for a better price through Internet.

This paper utilizes fuzzy logic to develop a bargaining model for such activities. The model supports buyers to make group decision to set up their bargaining strategy; instead of using static rules, buyers can customize their fuzzy rule base that can infer to produce negotiation proposals to bargain with sellers.

Experimental results show that (1) the prototype system with the fuzzy function is easy to use; (2) people enjoy online bargaining for better prices; (3) they think that online bargaining is very important and inevitable for electronic markets in the future.
\end{abstract}

Keywords: Group Purchasing, Collective Purchasing, Bargaining, Fuzzy Logic, Electronic Commerce

\section{Introduction}

Online group purchasing or collective purchasing is the activity in which people who desire to buy the same merchandises join together [1] so that they can bargain [2][9] with sellers for a better price through Internet.

However, the service of group bargaining for online group purchasing has not really been provided by commercial electronic stores yet. Currently, prices for online group purchasing are only decided by pricequantity functions or (price, quantity) tables which are defined by sellers [3][4][5]. Although this approach reduces the complexity of online group purchasing, the prices are still decided by sellers after all. Therefore, we think that buyers should have the right to group together and bargain for better prices, just like that in traditional markets.
For this sake, we develop an online bargaining model [10] that supports buyers to make group decision and automatically generate proposals to bargain with sellers. We utilize fuzzy logic [6][7][8] to develop the model. It first fuzzifies buyers' input, and then uses fuzzy rule base to infer to a fuzzy concession rate, which will be defuzzified to decide how much to concede in the next proposal.

In addition, the bargaining model is adaptive. It supports buyers to set up their bargaining strategy at the beginning, including deciding some important factors for bargaining, and even customizing their own fuzzy rule base. This is because every individual buyer is different, so is the group they form. A static rule base is not appropriate to use for every group.

A prototype system [10] for this model has been developed for experiments. Results show that the prototype with the fuzzy function is easy to use; people enjoy online bargaining and they believe that online bargaining is very important and inevitable for electronic markets in the future.

\section{The Bargaining Model}

The bargaining model for group purchasing is illustrated by the flow chart in Figure 1. It is described from the buyer's point of view. Each numbered task in the figure is described as follows:

1. Set up buyers' bargaining strategy (i) determine price related values.

Every buyer inputs their (a) bid for the first proposal to the seller; (b) highest acceptable price for the merchandise; (c) most concession rate between two consecutive proposals. The constraint is that the value of (a) should be less than that of (b); the value of (c) is a rate which is during $[0,1]$. With these three classes of input from all individuals, we get the minimum value of each class for the group to use in the bargaining. These three values are called (1) the 
bid of the group's first round proposal; (2) the group's highest acceptable price; (3) the group's most concession rate between two consecutive proposals.

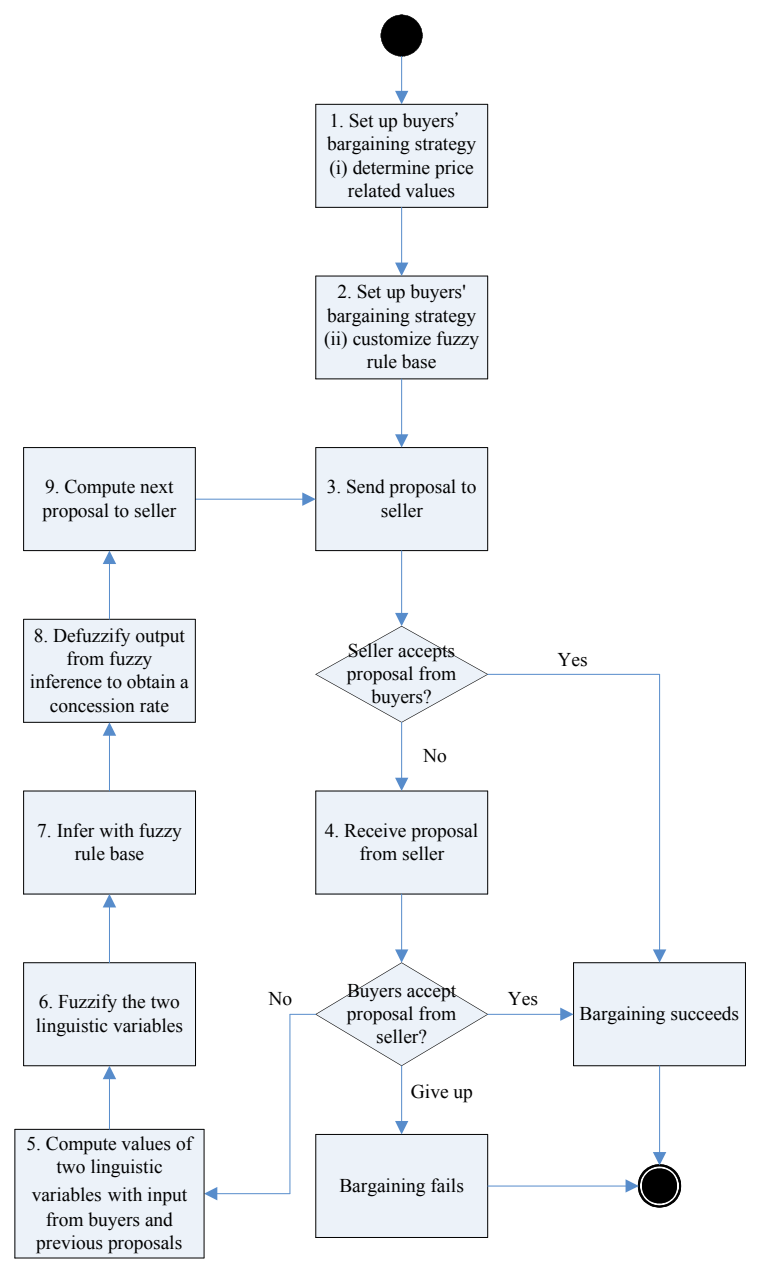

Fig. 1: The bargaining process for buyers

2. Set up buyers' bargaining strategy (ii) customize fuzzy rule base

The fuzzy rule base is established with three variables. (1) $A$ : the group's satisfaction degree to the proposal from the seller; (2) $B$ : the ratio for the difference between buyers' and seller's proposals; (3) $C$ : the group's concession rate. These three variables are called linguistic variables of the fuzzy system; the first two serve as the input of the fuzzy inference machine and the last as its output, whose upper bound is the group's most concession rate between two consecutive proposals.

In this task, each buyer first considers which of the first two variables has more impact on the last one. Then, the technique of "Conjoint Analysis" is employed to compute weight $w_{i}$ of these two variables, and these weights will be used to establish the customized fuzzy rule base. This is described as follows:

Each of the three linguistic variables has a linguistic term set consisting of 5 terms: NB (Negative Big), NS (Negative Small), ZO (Zero), PS (Positive Small) and PB (Positive Big), and they are mapped to integers $1,2,3,4$ and 5, respectively. We use function $f:\{\mathrm{NB}, \mathrm{NS}, \mathrm{ZO}$, $\mathrm{PS}, \mathrm{PB}\} \rightarrow[1,5]$ to represent the mapping.

The format of each inference rule is

\section{If $(A$ is $x) \&(B$ is $y)$ Then ( $C$ is $z$ ),}

where $A$ and $B$ are the input linguistic variables; $C$ is the output variable; $x, y, z \in\{\mathrm{NB}, \mathrm{NS}, \mathrm{ZO}$, $\mathrm{PS}, \mathrm{PB}\}$. Therefore, the establishment of the fuzzy rule base is to finish the table as shown in Table 1. The formula to obtain the value of $C$ is:

$$
z=f^{-1}\left(g\left(w_{1}^{\star} f(x)+w_{2}^{\star} f(y)\right)\right),
$$

where $g$ represents the function to round the input number to the nearest integer; $w_{1}+w_{2}=1$. Table2 shows a customized rule base.

Table 1: The empty fuzzy rule base

\begin{tabular}{||c|c|c|c|c|c||}
\hline \multicolumn{1}{|c|}{${ }^{A}$} & NB & NS & ZO & PS & PB \\
\hline NB & & & & & \\
\hline NS & & & & & \\
\hline ZO & & & & & \\
\hline PS & & & & & \\
\hline PB & & & & & \\
\hline
\end{tabular}

Table 2: A customized fuzzy rule base

\begin{tabular}{||c|c|c|c|c|c||}
\hline$C^{A}$ & NB & NS & ZO & PS & PB \\
\hline NB & NB & NS & NS & ZO & PS \\
\hline NS & NB & NS & ZO & ZO & PS \\
\hline ZO & NS & NS & ZO & PS & PS \\
\hline PS & NS & ZO & ZO & PS & PB \\
\hline PB & NS & ZO & PS & PS & PB \\
\hline \hline
\end{tabular}

\section{Send proposal to seller}

The sent proposal is either the first round proposal from Task 1 or the other round proposal from Task 9. The content of the proposal at least contains the bid and the amount of the merchandise the group wants to purchase. Since the proposal contains the purchase amount, 
buyers can freely join or quit the group during the bargaining.

\section{Receive proposal from seller}

If the seller agrees on the proposal, the bargaining succeeds and the process terminates; otherwise, the seller will send an anti-proposal to buyers.

If all buyers accept this anti-proposal, the bargaining succeeds and the process terminates; if buyers cannot or do not want to continue for some reason, the bargaining is given up.

5. Compute two linguistic variables with input from buyers and previous proposals

With the anti-proposal from the seller, each buyer will input their satisfaction degree to this proposal. The degree is represented by integers from 0 to $10 ; 0$ means the least satisfaction level and 10 the most satisfaction level. Linguistic variable $A$, group's satisfaction degree, is computed as follows:

$$
A=\left(\sum S a_{i}{ }^{*} A m_{i}\right) / \sum A m_{i},
$$

where $\mathrm{Sat}_{\mathrm{i}}$ and $\mathrm{Am}_{\mathrm{i}}$ are the satisfaction degree and purchasing amount of buyer i, respectively. Linguistic variable $B$, the ratio for the difference between buyers' and seller's proposals, is formulated as follows:

$$
\mathbf{B}=\mathbf{P s _ { \mathrm { i } }}-\mathbf{P b _ { \mathrm { i } }} / \mathbf{P o} \text {, }
$$

where $P s_{i}$ is the seller's proposed price and $\mathrm{Pb}_{\mathrm{i}}$ is buyer's bid for the $i$ th-round proposal; Po is the original price of the merchandise.

6. Fuzzify the two linguistic variables

This is the first step of the fuzzy system. This step is to transform the crisp values of linguistic variables into grades of membership for linguistic terms of fuzzy sets. In this fuzzy system, each linguistic variable is designed with 5 linguistic terms $\{\mathrm{NB}, \mathrm{NS}, \mathrm{ZO}, \mathrm{PS}, \mathrm{PB}\}$. Each linguistic term has a membership function that is used to associate a grade to the linguistic term. The membership functions of the linguistic variables $A$ and $\mathrm{B}$ can be designed as in Figure 2 . For example, for $\mathrm{A}=8.5$, the grades of membership for these 5 linguistic terms $\{\mathrm{NB}$, NS, ZO, PS, PB $\}$ are $\{0,0,0,0.6,0.4\}$, while for $\mathrm{B}=0.2$, the grades are $\{0.2,0.8,0,0,0\}$.

\section{Infer with fuzzy rule base}

This is the second step of the fuzzy system. Infer with the customized fuzzy rule base produced in Task 2 . The inference method used is max-product method. The output of this method is the grades of membership for the 5 linguistic terms of linguistic variable $C$.
The max-product method has two stages: (1) generate the product of the grades of membership; (2) select the maximum value as the grades of membership for each linguistic term. For example, given grades of membership $\{0,0,0,0.6,0.4\}$ and $\{0,0,0,0.8,0.2\}$ for linguistic variables $A$ and $B$, respectively, the result of the first stage of max-product method is shown in Table 3, where $C_{i j}=A_{i} * B_{j}$. After the second stage, the grades of membership $\{0,0,0$, $0.48,0.32\}$ for linguistic variable $C$ are obtained because 0 is the maximum grade of membership for NB, NS and ZO, 0.48 for PS and 0.32 for PB.
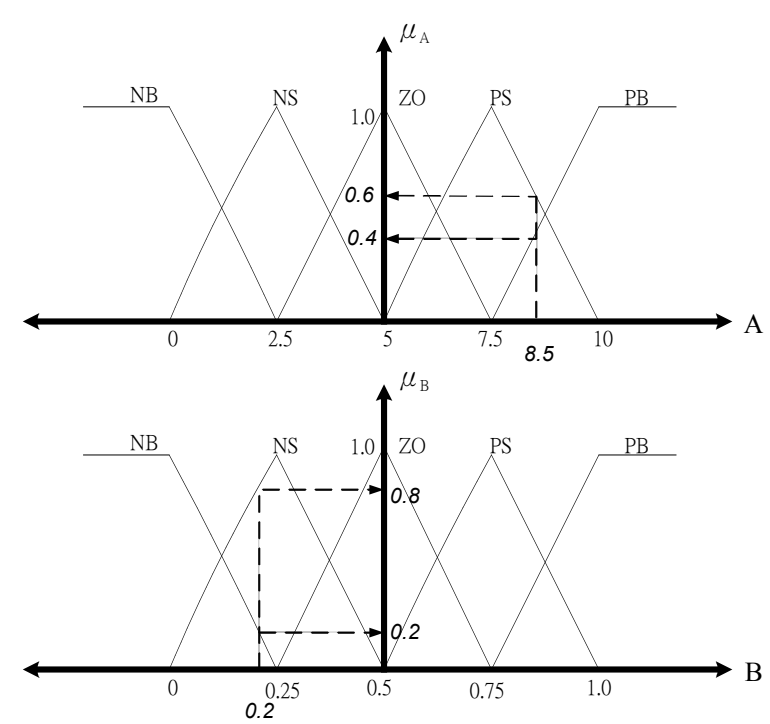

Fig. 2: Membership functions of linguistic variables $A$ and $B$

Table 3: Inference with max-product method

\begin{tabular}{||c|c|c|c|c|c||}
\hline \begin{tabular}{|c|c|}
$A$ \\
$B$
\end{tabular} & $\begin{array}{c}\mathrm{NB} \\
(0)\end{array}$ & $\begin{array}{c}\mathrm{NS} \\
(0)\end{array}$ & $\begin{array}{c}\mathrm{ZO} \\
(0)\end{array}$ & $\begin{array}{c}\mathrm{PS} \\
(0.6)\end{array}$ & $\begin{array}{c}\mathrm{PB} \\
(0.4)\end{array}$ \\
\hline $\mathrm{NB}(0)$ & $\mathrm{NB}(0)$ & $\mathrm{NS}(0)$ & $\mathrm{NS}(0)$ & $\mathrm{ZO}(0)$ & $\mathrm{PS}(0)$ \\
\hline $\mathrm{NS}(0)$ & $\mathrm{NB}(0)$ & $\mathrm{NS}(0)$ & $\mathrm{ZO}(0)$ & $\mathrm{ZO}(0)$ & $\mathrm{PS}(0)$ \\
\hline $\mathrm{ZO}(0)$ & $\mathrm{NS}(0)$ & $\mathrm{NS}(0)$ & $\mathrm{ZO}(0)$ & $\mathrm{PS}(0)$ & $\mathrm{PS}(0)$ \\
\hline $\mathrm{PS}(0.8)$ & $\mathrm{NS}(0)$ & $\mathrm{ZO}(0)$ & $\mathrm{ZO}(0)$ & $\begin{array}{c}\mathrm{PS} \\
(\mathbf{0 . 4 8})\end{array}$ & $\begin{array}{c}\mathrm{PB} \\
(\mathbf{0 . 3 2})\end{array}$ \\
\hline $\mathrm{PB}(0.2)$ & $\mathrm{NS}(0)$ & $\mathrm{ZO}(0)$ & $\mathrm{PS}(0)$ & $\begin{array}{c}\mathrm{PS} \\
(0.12)\end{array}$ & $\begin{array}{c}\mathrm{PB} \\
(0.08)\end{array}$ \\
\hline
\end{tabular}

8. Defuzzify output from fuzzy inference to obtain a concession rate

This is the last step of the fuzzy system. The defuzzification method adopted is Center of Gravity method. The output of this method is a crisp value of a linguistic variable, the $\mathrm{x}$-axis position of the gravity center of some areas 
which are derived from the grades of membership of the linguistic variable.

For this case, the output is a crisp value of linguistic variable $C$, the group's concession rate, denoted by $r_{i+1}$. The rate is used to compute the bid for the group's $(i+1)$ th-round proposal.

For example, assume the group's most concession rate between two consecutive proposals is 0.5 . The membership functions of linguistic variable $C$ is shown in Fig. 3. Given the grades of membership $\{0,0,0,0.48,0.32\}$ for linguistic variable $C$, apply the Center of Gravity method to defuzzify and obtain a crisp value 0.39 .

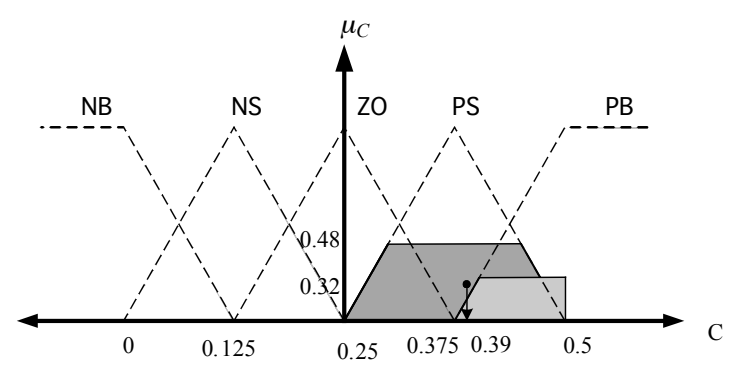

Fig.3: Membership functions of linguistic variable C

\section{Compute the next proposal to seller}

The buyers' next proposed bid for the $(i+1)$ thround proposal is denoted by $\mathrm{Pb}_{\mathrm{i}+1}$. It is calculated by

$$
\mathbf{P b}_{\mathrm{i}+1}=\mathbf{P b}_{\mathrm{i}}{ }^{*}\left(1+\mathbf{r}_{\mathrm{i}+1}\right) \text {, }
$$

where $\mathrm{Pb}_{0}$ is the bid of the group's first-round proposal generated in Task 1. After that, go to Task 3 to send out the next proposal that at least contains $\mathrm{Pb}_{\mathrm{i}+1}$ and the amount of the merchandise the group wants to purchase.

\section{Conclusion}

The contribution of this paper is the approach that we proposed for the online bargaining of group purchasing. A prototype system, shown in Fig. 4, for this model has been developed for experiments. Results show that the prototype with the fuzzy function is easy to use; people enjoy online bargaining and they believe that online bargaining is very important and inevitable for electronic markets in the future. However, the disadvantage is that the time group bargaining takes is a little bit longer.

Our future work is to improve the approach so that it has a better quality to compute the bid of proposals which is much closer to the common will of the group members.

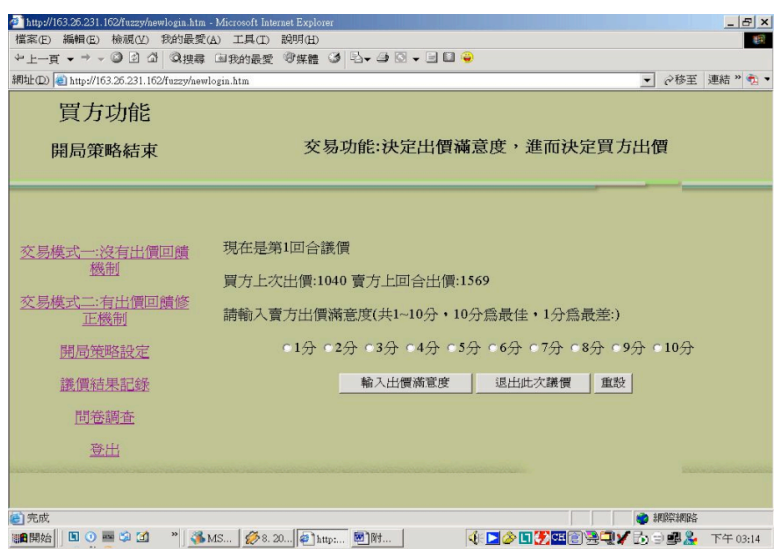

Fig. 4: A prototype bargaining system for experiments

\section{References}

[1] Soe-Tsyr Yuan and Yu-Hsin Lin, Credit-based Group Negotiation for Aggregate Sell/Buy in eMarkets, Electronic Commerce Research and Application, vol. 3, pp.74-94, 2004.

[2] Abhinay Muthoo, Bargaining Theory with Applications, Cambridge University Press, 1999.

[3] http://www.collectivepurchasing.co.uk/

[4] http://www.softking.com.tw/

[5] http://www.groupbuycenter.com/

[6] John Yen and Reza Langari, Fuzzy Logic: Intelligent, Control, and Information, Prentice Hall, 1999.

[7] George J. Klir and Bo Yuan, Fuzzy Set and Fuzzy Logic: Theory and Application, Prentice Hall, 1995.

[8] Kazuo Tanaka and T. Niimura, An Introduction to Fuzzy Logic for Practical Applications, Springer, 1996.

[9] T. Liang and H. Doong, Effects of Bargaining in Electronic Commerce, Proceedings of International Workshop on Advanced Issues of e-Commerce and Web-based Information Systems, 1998.

[10] Chien-Lan Hung and Ping-Wen Chen, A Bargaining Model of Collective Purchasing, master thesis, Department of Information Management, Southern Taiwan University of Technology, 2005. 